\title{
Heat pain and pressure pain
}

DIANA R. HASLAM

UNIVERSITY OF BRISTOL

A significant positive relationship was found between heatpain and pressure-pain threshold values determined on the forehead and tibia respectively. The finding of a relationship between threshold values of pain of different categories from different body areas supports some results reported by Keele (1954). It also demonstrates that it is possible to assess a "general pain threshold" for a person in the sense that for a given $S$ there is a correspondence between threshold values determined by means of various procedures and at various sites.

In experimental studies concerned with the assessment of pain threshold there is always some doubt as to whether a "true threshold" can be measured. It has been argued elsewhere (Haslam, in press) that even if absolute pain threshold cannot be determined, a case can be made that individual differences in pain threshold can. In order to overcome some of the problems inherent in the study of experimental pain, an optimum interval for the assessment of heatpain threshold has been suggested by Haslam and Thomas (1967). This interval is called "optimum" because it gives rise to the most reliable heat-pain threshold values.

Another method of measuring pain threshold which is thought to be reliable (Merskey \& Spear, 1964) is by means of a pressure algometer. Keele (1954) has found a positive relationship between threshold values determined by this method and those determined by various other methods. The other methods were Libman's (1934) test (pressure on the styloid process), Harrison \& Bigelow's (1943) modification of Lewis's (1942) ischaemic test (isotonic squeezing of a sphygmomanometer bulb at a metronome rate of 1 per sec), and Hollander's (1939) test (pressure on the upper arm from a metal grater under an inflatable cuff).

In view of Keele's findings, it was thought that it would be interesting to determine whether there was also a positive relationship between pressure-pain and heat-pain threshold values. Accordingly, the following experiment was carried out, in which pressure was applied to the tibia and radiant heat to the forehead.

\section{Method}

Heat-pain threshold. Heat-pain threshold was assessed by means of a modified Hardy-Wolff (1952) radiant heat apparatus. Details of this and the procedure used are given elsewhere (Haslam, 1965).

For all Ss the energy level of the first stimulus was $98 \mathrm{mcal} / \mathrm{sec} / \mathrm{cm}^{2}$, which the majority of Ss described as warm. The intensity of each successive stimulus was increased by approximately $16 \mathrm{mcal} /$ $\mathrm{sec} / \mathrm{cm}^{2}$, which is the optimum interval in the assessment of heat-pain threshold (Haslam \& Thomas, 1967). This procedure was continued until the $S$ reported that a feeling of heat had changed into a small stab of pain at the end of the $3 \mathrm{sec}$. exposure.

Pressure-pain threshold. Pressure-pain threshold was assessed by means of a pressure algometer similar to that described by Keele (1954) and by Merskey \& Spear (1964). This consists of a metal box containing a spring which is attached to a plunger. It is calibrated in kilograms (from 0-8) and readings are made on a scale indicating the force applied at the tip of the plunger. The tip is metal and has a flat circular end of $0.5 \mathrm{~cm}$ diameter.

The instrument was applied horizontally to the tibia and pressure was increased at a constant rate of approximately $1 \mathrm{~kg}$ per sec. The $\mathrm{S}$ was told that he would feel increasing pressure which would become painful, and he was asked to report as soon as the feeling of pressure turned into one of pain: The test was repeated on different areas of the tibia until consistent readings were obtained on three occasions.

Thirty-two Ss (16 male and 16 female) were drawn from the administrative staff and the student body of the University. Their mean age was 22.9 years.

Half the Ss underwent heat-pain threshold assessment first and the other half underwent pressurepain threshold assessment first. The two sessions were on different days.

\section{Results and Discussion}

A positive correlation (rho $=+0.45$ ) was found between heat-pain and pressure-pain threshold values. This is significant at the 0.02 level of confidence.

Table 1 shows the mean threshold values and ranges for males and females for both types of threshold determination. There is no significant difference between male and female threshold values for either heat-pain or pressure-pain.

Table 1. Mean heat-pain and pressure-pain threshold values for males and females.

\begin{tabular}{|c|c|c|c|c|c|c|}
\hline & Number of $\mathrm{S}_{\mathrm{s}}$ & Mean age of $S_{s}$ in years & $\begin{array}{l}\text { Mean heat-pain } \\
\text { threshold in } \mathrm{mc} / \mathrm{sec} / \mathrm{cm}^{2}\end{array}$ & Range & $\begin{array}{c}\text { Mean pressure-pain } \\
\text { threshold in kgs. }\end{array}$ & Range \\
\hline $\begin{array}{l}\text { Males } \\
\text { Females }\end{array}$ & $\begin{array}{l}16 \\
16\end{array}$ & $\begin{array}{l}23.9 \\
21.8\end{array}$ & $\begin{array}{l}218 \\
221\end{array}$ & $\begin{array}{l}176-283 \\
156-264\end{array}$ & $\begin{array}{l}3.19 \\
2.78\end{array}$ & $\begin{array}{l}2.03-5.03 \\
1.65-4.83\end{array}$ \\
\hline
\end{tabular}


The mean heat-pain threshold for the total group is $220 \mathrm{mcal} / \mathrm{sec} / \mathrm{cm}^{2}$. This is the value previously suggested as being the average heat-pain threshold for the whole population (Thomas, 1966; Haslam \& Thomas, 1967).

The significant positive correlation between heatpain and pressure-pain threshold values supports Keele's finding of a relationship between pain threshold values determined by means of various procedures and at various sites, and it demonstrates that it is possible to assess a "general pain threshold" for a person in the sense that for a given $S$ there is a relationship between threshold values of pain of different categories.

\section{References}

HARDY, J. D., WOLFF, H. G., \& GOODELL, H. Pain sensations and reactions. Baltimore: The Williams \& Wilkins Co., 1952
HARRISON, I., \& BIGELOW, N. H. Quantitative studies of visceral pain produced by the contraction of ischemic muscle. Proc. Assoc. Res. nen. ment. Dis., 1943, 23, 154-165.

HASLAM, D. R. The influence of stinulus scale-interval upon the assessment of pain threshold. Quart. J. exp. Psychol, 1965, 17, 65-68.

HASLAM, D. R. Some anomalies in the study of experimental pain. (In press.)

HASLAM, D. R., \& THOMAS, E. A. C. An optimum interval in the assessment of pain threshold. Quart. J. exp. Psychol., 1967, 19, 5458. HOLLANDER, E. A clinical gauge of sensitivity to pain. J. Lab. clin Med., 1939, 24, 537-538.

KEELE, K. D. The pressure algometer. Lancet, 1954, 1, 636-639. LEWIS, T. Pain. New York: MacMillan, 1942.

LIBMAN, E. Observations on individual sensitiveness to pain. J. Amer. med. Assoc., 1934, 102, 335-341;

MERSKEY, H., \& SPEAR, F. G. The reliability of the pressure algometer. Brit. J. soc. clin. Psychol, 1964, 3, 130-136.

THOMAS, E. A. C. On determining pain thresholds using the limiting method. Quart. J. exp. Psychol., 1966, 18, 270-272. 